\title{
semFYC y MEDIFAM
}

a Sociedad Española de Medicina de Familia y Comunitaria (semFYC) tiene como fin fundamental el fomentar el progreso de la Medicina de Familia, divulgando e impulsando los conocimientos de la especialidad y sus principios, así como contribuir al desarrollo de una Atención Primaria de calidad.

Para obtener este fin fundamental la semFYC realiza actividades de carácter profesional y científico muy variadas: asistenciales, formativas, investigadoras, divulgativas y también de análisis y debate.

En este marco que define a nuestra sociedad, la junta directiva de semFYC siempre ha intentado que este tipo de contenidos propios de la Medicina de Familia llegara a sus socios.

Durante los últimos diez años se han realizado esfuerzos por llegar a un acuerdo con la revista MEDIFAM para que se estableciera una relación con semFYC. Fruto del esfuerzo de las juntas directivas que presidieron José Ramón Vázquez y Albert Planes, hoy es posible que los socios de semFYC reciban la revista MEDIFAM. De esta manera semFYC incrementa el servicio a sus socios en el campo de las publicaciones periódicas. Desde enero de 2001 recibiremos las dos revistas de originales más importantes en el ámbito de la Atención Primaria (MEDIFAM y Atención Primaria) en nuestro país y la revista Dimensión Humana.

Además el acuerdo tiene un valor añadido para la semFYC en su conjunto. La Junta Directiva de semFYC expresará, a través de la línea editorial de la revista MEDIFAM, sus opiniones acerca de todos los aspectos científicos y profesionales que afecten a la Medicina de Familia en nuestro país y en nuestro entorno geográfico y cultural más proximo: Unión Europea e Iberoamérica. Esto convierte a la revista MEDIFAM en órgano de difusión de semFYC.

Desde la junta directiva de semFYC creemos que lo importante son los encuentros, y entendemos que esta andadura que se inicia hoy, es el primer encuentro de muchos otros encuentros que se producirán cuando 14.000 médicos de familia lean, debatan, envíen originales y como no, critiquen lo publicado en esta revista.

Esperamos que todos juntos semFYC y MEDIFAM, Medifam y semFYC, alcancemos la meta ansiada por todos los médicos de familia: el desarrollar plenamente nuestro perfil profesional en el servicio a los ciudadanos.

AMALIA VELÁZQUEZ GARCÍA Presidenta semFYC 